\title{
Carbon Fibre Reinforced Shape Memory Polymer Composites for Deployable Space Habitats
}

\author{
H. M. C. M. Herath, J. A. Epaarachchi, M. M. Islam, J. Leng
}

\begin{abstract}
Intelligent material shape memory polymers (SMPs) and their composites are capable of memorizing and recovering the original shape upon exposure to a particular external stimulus. This paper presents the mechanical properties, thermomechanical behaviour and the shape memory characteristics of $0 / 90$ woven carbon fibre reinforced shape memory composite. The results revealed that the superlative mechanical properties of carbon fibres as a reinforcement has enhanced the strength of the SMP composite (SMPC) to be applicable for space engineering innovations. Furthermore, the recovery behaviour of $90^{\circ}$ bended SMPC specimens have been investigated by exposing to heated air and near infrared radiation. Both stimulus methods have shown almost $98 \%$ shape recovery. In addition, a model of a cubic deployable structure has been fabricated and respective shape programming and recovery behaviours have been investigated based on the enclosed volume. Interestingly, the deployable structure has been programmed in to almost three times smaller volume and very nearly recovered to its original shape under vacuumed conditions. Accordingly, the carbon fibre reinforced SMPCs can be used to produce deployable space habitats to fabricate on earth, compress and pack in a spacecraft, transport to an outer space location and ultimately deploy in to the original shape.
\end{abstract}

Keywords: Shape Memory Polymer Composites, Carbon Fibres, Deployable Structures, Space Habitats

\section{Introduction}

Shape memory polymers and their composites have an interesting capability of keeping a temporary shape and then recovering the original shape when subjected to an external stimulus such as heat, electricity, magnetic field, moisture, chemical stimulus, microwave and light, where the most common activation method is by heat. At a high temperature greater than glass transition temperature $(\mathrm{Tg})$, the material is programmed to the desired shape. Then, it is held fixed and cooled down until the material turns into a frozen polymer at a low temperature. Due to relatively higher stiffness of the glassy phase compared to the rubbery phase, the strain changes slightly and material will acquire the fixed shape. Finally, increasing the temperature over $\mathrm{Tg}$, the strain relaxes and the shape will be recovered. This cycle is called a stress-free strain recovery of SMPs or its composites [1].

Since the discovery of the shape memory polymers in 1980s, the global research interest in these materials has been rapidly growing [2], because of the inimitable advantages of good manufacturability, high shape deformability, large recoverability, good biodegradability, and an easily tailorable glass transition temperature (Tg) [3]. These advantages, make the SMPs very competitive materials to replace the shape memory alloys (SMAs), which are known to have good mechanical properties, relatively expensive to manufacture and have relatively high density [4]. Relatively low modulus and recovery stress are the inherent drawbacks of the SMPs that caused them to be less competitive than SMAs in the past [5]. However, when the SMPs are reinforced with fibres (SMPCs), significant improvements have occurred in the mechanical properties [6]. In addition to the

\footnotetext{
Eng. H. M. C. M. Herath, AMIE(SL), B.Sc. Eng. (Ruhuna), M.Eng. (Moratuwa), School of Mechanical and Electrical Engineering, Centre for Future Materials, University of Southern Queensland, Australia. Email: Madhubhashitha.Herath@usq.edu.au iD ORCID ID: https://orcid.org/0000-0002-6796-0802
}

Eng. (Assoc Prof.) J. A. Epaarachchi, C. Eng., MIE(SL), B.Sc. Eng. (Peradeniya), M.Eng.Sc. (UNSW), Ph.D. (Newcastle), Associate Professor, School of Mechanical and Electrical Engineering, Centre for Future Materials, University of Southern Queensland, Australia. Email: Jayantha.Epaarachchi@usq.edu.au

D ORCID ID: https://orcid.org/0000-0001-6472-9405

Eng. (Dr.) M. M. Islam, CPEng., MIE(Aust), B.Sc. Eng. (IT Khulna), M.Eng. (Kyushu), Ph.D. (Newcastle), Senior Lecturer, School of Mechanical and Electrical Engineering, Centre for Future Materials, University of Southern Queensland, Australia.

Prof. J. Leng, FSPIE, FlnstP, FRAeS, FIMMM, B.Sc. (HIT), Ph.D. (HIT), Director, Center For Smart Materials and Structures, Harbin Institute of Technology, China. 
strength and durability, the low density of the SMPCs make it tolerable as a space material. However, endure uniquely and stay steady in the presence of micrometeoroids, space debris, extreme radiation, temperatures and vacuum, while maintaining the structural permanence are the most challenging concerns on selecting lightweight materials for space applications [7]. Therefore, the researchers have investigated the effects of ultra violet (UV) and $\gamma$ radiation, on impact failure and cycle-life of different SMPCs. It has been noticed that the shape memory effect of the SMPCs does not degrade considerably due to such circumstances [8].

When the space travellers stay for long durations in outer space, a shelter or habitat must be used to protect them from extreme space environment conditions. Such habitats can be constructed on earth and transported to the space. Thus the development of deployable structures becomes important as it reduces the occupied room in spacecraft and makes the best use of the deployed volume in space [9]. SMPC is one of the lightweight materials to satisfy the purpose, as it can be packaged and stowed in a smaller volume and deployed using a particular stimuli in space. This paper describes the experimental investigations on mechanical properties, thermomechanical behaviour and shape memory characteristics of $0 / 90$ woven carbon fibre reinforced SMPCs. Moreover, the shape fixity and shape recovery behaviour of a cube shaped deployable structure are presented.

\section{Material Preparation and Experimental Methods}

The carbon fibre reinforced shape memory epoxy prepreg used for this research was supplied by the Harbin Institute of Technology (HIT), China. The detailed chemical composition of the SMP matrix is proprietary to Center for Composite Materials and Structures of HIT. As illustrated in Figure 1, four laminations of prepreg containing 0/90 woven fibre mesh were cured under vacuum bagging under $7 \mathrm{MPa}$ for 9 hours at $80{ }^{\circ} \mathrm{C}, 100{ }^{\circ} \mathrm{C}$ and $150{ }^{\circ} \mathrm{C}$ respectively, with equal time spacing. The formed sheets (thickness: $1.2 \mathrm{~mm}$ ) were cut in to rectangle shapes using a diamond saw, according to the dimensions illustrated in Figure 1 (d).

Mechanical properties and thermomechanical characteristics of the SMPCs have been investigated experimentally and respective test setups are shown in Figure 2. TA instruments dynamic mechanical analyzer (DMA Q800) with single cantilever clamping has been used to investigate the thermomechanical behaviour. The multi-frequency strain mode has been used to determine the $\mathrm{Tg}$, loss modulus and storage modulus. The DMA specimen was subjected to a temperature ramp of $5{ }^{\circ} \mathrm{C} / \mathrm{min}$, from $35^{\circ} \mathrm{C}$ to $140^{\circ} \mathrm{C}$ under a frequency of $1 \mathrm{~Hz}$. Moreover, the stress-free strain recovery of the SMPC has been investigated under DMA strain rate mode. Respective DMA program begins with a temperature ramp of $5^{\circ} \mathrm{C} / \mathrm{min}$ up to $130^{\circ} \mathrm{C}$ with zero strain, continued by a constant temperature of $130{ }^{\circ} \mathrm{C}$ for 4 mins with an intermediate strain ramp of $1 \% /$ min up to $2 \%$ strain, continued by a temperature ramp of $-4.3^{\circ} \mathrm{C} / \mathrm{min}$ down to 36 ${ }^{\circ} \mathrm{C}$, followed by a constant temperature with $2 \%$ constant strain. Subsequently, constrain was released and the temporary fixed shape was
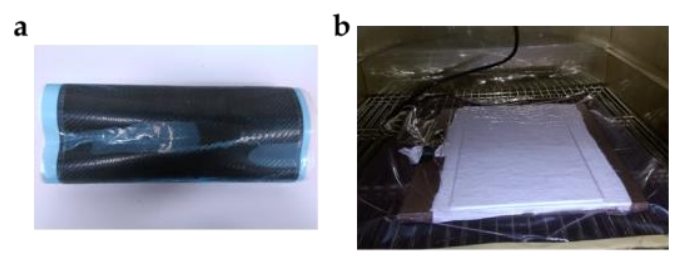

c

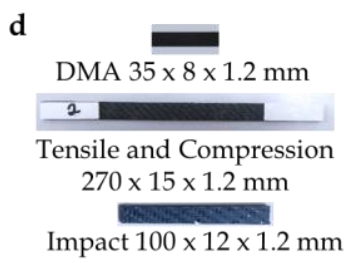

Figure 1 - Material Preparation Process (a) Prepreg Raw Material (b) Vacuum Bagged Curing Process (c) Cured SMP Sheet (d) Standard Test Specimens

a

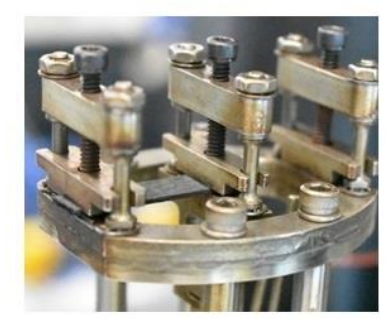

c

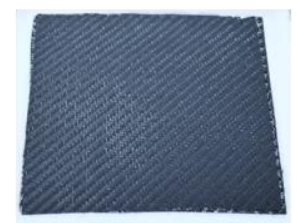

b

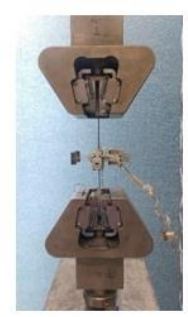

d

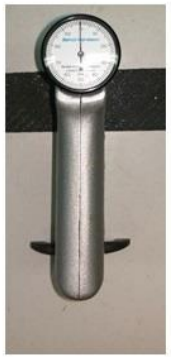

Figure 2 - Mechanical and Thermomechanical Experiments (a) DMA Testing (b) Tensile and Compression Testing (c) Drop Weight Impact Testing (d) Hardness Testing 
achieved. Finally, the specimen was subjected to a temperature ramp of $5{ }^{\circ} \mathrm{C} / \mathrm{min}$ up to $130{ }^{\circ} \mathrm{C}$ and isothermal for $30 \mathrm{~min}$ and the strain recovery was observed. By using the MTS 100 $\mathrm{kN}$, Insight Electromechanical Testing System tensile and compression tests have been carried out under ISO 527-5:2009 [10] and ASTM D6641 [11] test standards respectively. Instron Dynatup Drop Weight Impact Testing Instrument (8200) and Barcol Impressor Hand-held portable hardness tester (GYZJ-934-1) have been used to test the impact energy and hardness respectively. All mechanical tests have been conducted at room conditions $\left(\sim 25^{\circ} \mathrm{C}\right.$ and $\sim 100$ $\mathrm{kPa})$.

As illustrated in Figures 3 (a) and (b), the shape recovery behaviour of the bended SMPC specimens have been investigated by exposing to near infrared radiation (808 $\mathrm{nm}$ wavelength, $2 \mathrm{~W} / \mathrm{cm}^{2}$ intensity) and heated air $\left(150{ }^{\circ} \mathrm{C}\right.$ temperature, $0.5 \mathrm{~m}^{3} / \mathrm{min}$ flow rate) respectively. For each case, the specimen $(60 \times 8 \times 1.2 \mathrm{~mm}$ strip) was bent $90^{\circ}$ at the middle and one end was clamped while the other end was free as shown in Figure 3 (c). The cross section along the bend was a rectangle and bend radius was approximately $5 \mathrm{~mm}$. The recovery angles were video recorded using a Nikon D3400 DSLR camera (frame size: $1920 \times 1080$, frame rate: 60P). Subsequently, the recovery angles were measured, using "Gwyddion" open source image analysis software. Simultaneously, the temperature profiles of the specimens (from bend location to free end) have been captured using a FLIR A65 Thermal Imaging Camera.

A model of a cube shaped deployable structure has been fabricated by using 12 SMPC strips with $6 \mathrm{~mm}$ width and $1.2 \mathrm{~mm}$ thickness. The strips were cut in to $65 \mathrm{~mm}$ length and jointed using "Selleys Ultra Repair" temperature resistant adhesive. The 3D drawing of the fabricated deployable structure is shown in Figure 4 (a). The fabricated model was heated up to $130^{\circ} \mathrm{C}$ by using the oven and programed in to the shape shown in Figure 4 (b). Subsequently, the programmed structure has been kept in the oven at $130^{\circ} \mathrm{C}$ under $80 \mathrm{kPa}$ vacuum. As shown in Figure 5 (a), respective shape recovery behaviour has been video recorded, using a Nikon D3400 DSLR camera. As illustrated in Figure 5 (b), the enclosed volumes of the programmed shape and recovered shape have been measured by using a ROMER Multi Gage coordinate measuring arm.

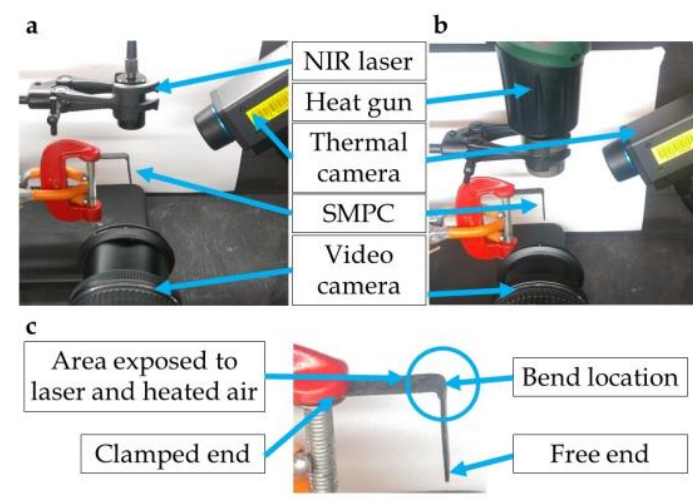

Figure 3 - Experimental Setup for Shape Recovery Behaviour of $90^{\circ}$ Bended SMPC Specimens (a) By NIR Laser (b) By Heated Air (c) $90^{\circ}$ Bended Specimen

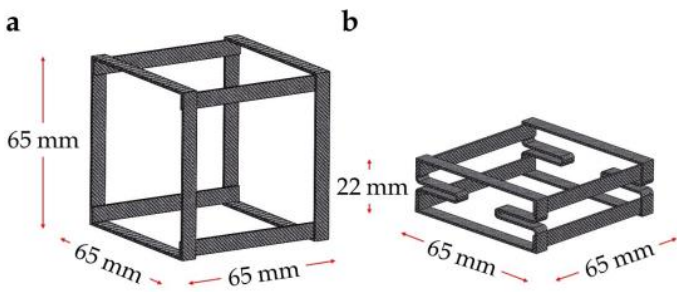

Figure 4 - 3D Model of the Cubic Deployable Structure (a) Original Shape (b) Programmed Shape
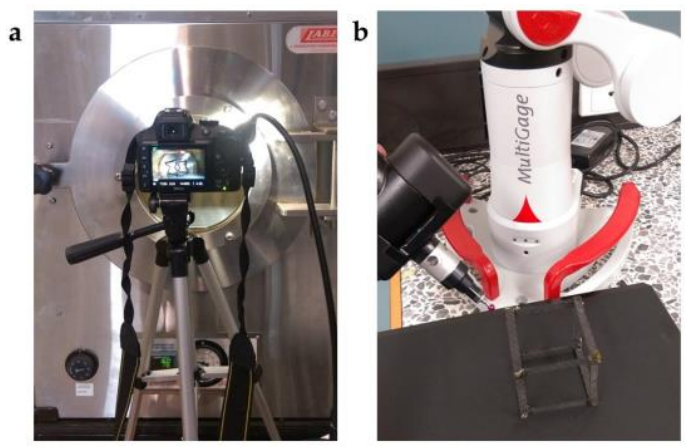

Figure 5 - Experimental Setup for the Shape Recovery of Deplorable Structure (a) Shape Recovery Process in Vacuum (b) Measuring of Enclosed Volume

\section{Results and Discussion}

Shape memory polymers and their composites have evolved intensely and represent a fast growing branch of smart materials research. The material properties and shape memory behaviour of the carbon fibre reinforced SMPC and its application of a deployable structure are discussed in this section. The prepared SMPC consisted with $\sim 30 \%$ mass fraction of carbon fibres. A total mass reduction of $\sim 18 . \%$ has been noticed during the vacuum bagged curing process. This has occurred due to the absorption 
of resin by the bleeder layer, which flowed through the peel ply.

\subsection{Thermomechanical Behaviour}

Viscoelastic materials can exhibit both viscous and elastic behaviour. Therefore, such materials can be seen as a combination of both ideal types of materials, purely viscous fluids and ideally elastic solids. The dynamic mechanical analysis (DMA) is used to evaluate both elastic and viscous material responses simultaneously.

The glass transition temperature $(\mathrm{Tg})$ is the temperature region where the polymer transfer from a hard glassy phase to a soft rubbery phase. The onset point of the storage modulus curve or peak of the loss modulus curve or peak of the tan delta curve is often employed to define the $\mathrm{Tg}$. Figure 6 (a) illustrates the storage modulus, loss modulus and tan delta curves for the SMPC. Accordingly, Tg of the material can be defied as $98{ }^{\circ} \mathrm{C}$ by considering the peak of the tan delta curve, which gives the maximum possible temperature value for $\mathrm{Tg}$. The storage modulus indicates the ability to store deformation energy under elastic manner. The SMPC shows higher storage modulus at lower temperatures and low
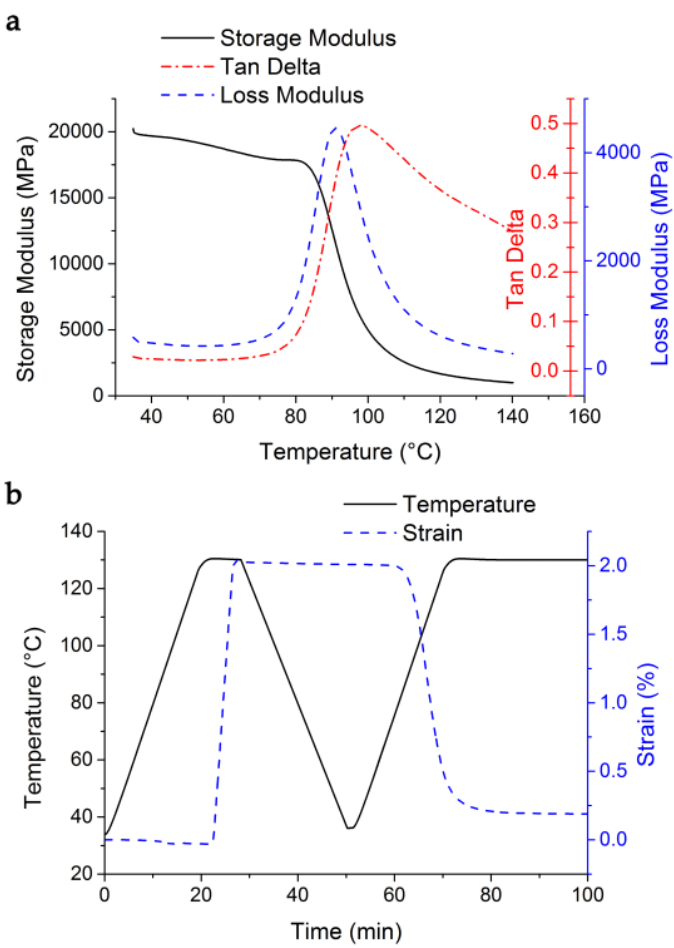

Figure 6 - Thermomechanical Behaviour of SMPC (a) Storage Modulus, Loss Modulus and Tan Delta Curves (b) Programming and Stress-free Strain Recovery
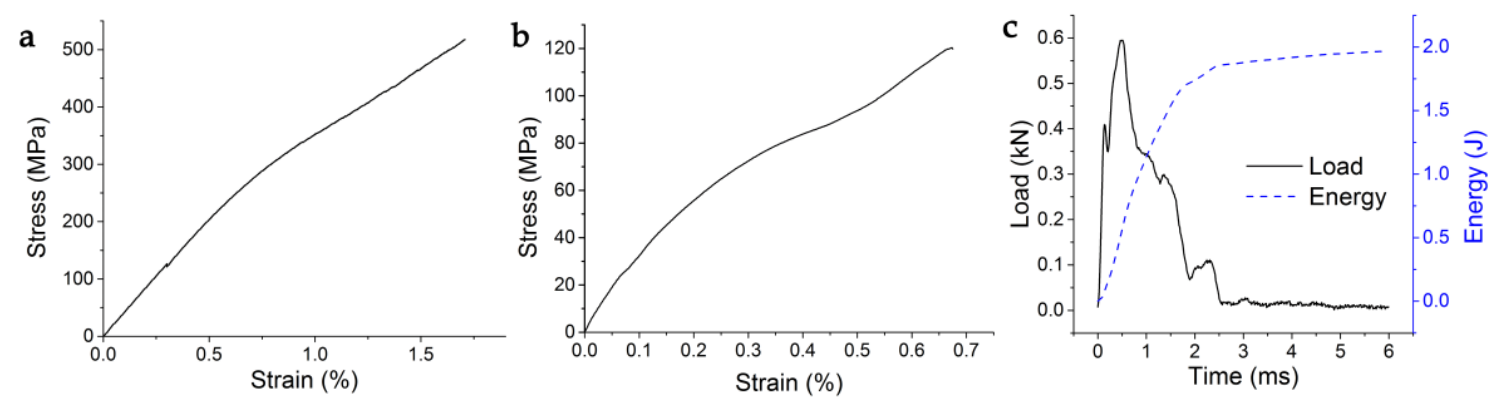

Figure 7 - Mechanical Properties of the SMPC (a) Tensile Stress vs Strain (b) Compression Stress vs Strain (c) Impact Energy

Table 1 - Physical Properties of the SMPC and General Space Materials

\begin{tabular}{|l|c|c|c|c|c|c|}
\hline & SMPC & $\begin{array}{c}\mathrm{CYCOM}^{\circledR} \\
934^{*}[13]\end{array}$ & $\begin{array}{c}\text { HexPly } \\
\text { M91** }\end{array}{ }^{\circledR}[4]$ & $\begin{array}{c}\text { Ti6Al4V } \\
{[15]}\end{array}$ & $\begin{array}{c}\text { Al 2090 } \\
{[15]}\end{array}$ & $\begin{array}{c}\text { Al 8090 } \\
{[15]}\end{array}$ \\
\hline Density $\left(\mathrm{g} / \mathrm{cm}^{3}\right)$ & 1.3 & - & 1.58 & 4.42 & 2.59 & 2.54 \\
\hline $\begin{array}{l}\text { Tensile strength } \\
(\mathrm{MPa})\end{array}$ & 517 & $1586-1792$ & 3520 & 1000 & 550 & 450 \\
\hline $\begin{array}{l}\text { Elastic modulus } \\
(\mathrm{GPa})\end{array}$ & 42 & $124-138$ & 176 & 114 & 76 & 77 \\
\hline $\begin{array}{l}\text { Compressive } \\
\text { strength }(\mathrm{MPa})\end{array}$ & 120 & $1517-1724$ & 1880 & - & - & - \\
\hline $\begin{array}{l}\text { Hardness } \\
\text { (Brinnell) }\end{array}$ & $\sim 39$ & - & - & $\sim 336$ & 150 & 121 \\
\hline
\end{tabular}

* CEM Product Codes Hy-E 1034K, Hy-E 3034K, Hy-E 1334G

** M91/34\%/UD194/ IM10-12K 
modulus at higher temperatures. This happens because of the entropy elasticity caused by the micro-Brownian movement in the rubbery phase [6]. Figure 6 (b) illustrates the shape programming and stress-free strain recovery of the SMPC. According to the definitions of Fejös et al. [12], it can be quantified that the SMPC has shown excellent strain fixity ratio of almost 100 $\%$ and the strain recovery ratio of $90.55 \%$. Interestingly, no spring back effect has shown after the shape programing phase.

\subsection{Mechanical Properties}

Higher strength and durability are two of the most critical factors for selecting lightweight materials for space applications. Figures 7 (a) and $(\mathrm{b})$ illustrate the unidirectional $\left(0^{\circ}\right)$ tensile and compression curves of the SMPC. It has been observed that both stress-strain curves tensile and compressive, present a non-linear trend. Such behaviour can occur due to voids between laminae and progressive failures of fibres due to local bending at void locations [16]. The impact energy absorbance of the SMPC is shown in Figure 7 (c). The fracture energy measured by drop weight impact tester was 1.97 $\mathrm{J}$. In addition, the hardness measured by Barcol Impressor scale was 56, which is approximately 39 in Brinnell scale. Table 1 compares the mechanical properties of the SMPC (average of 5 tests) with existing space materials. CYCOM $^{\circledR}$ 934 and $\mathrm{HexPly}{ }^{\circledR} \mathrm{M} 91$ are carbon fibre reinforced commercial prepreg materials which are used for structural aircraft components and space structures. The grade 5 Titanium alloy Ti6Al4V and Aluminium alloys Al 2090 and Al 8090 are used to manufacture aircraft structural components. Accordingly, SMPC is the most light weight material which shows the lowest density of $1.3 \mathrm{~g} / \mathrm{cm}^{3}$. This benefits to transport such materials from earth to space. It can be identified that the SMPC has poor mechanical properties compared to $\mathrm{CYCOM}^{\circledR}$ 934, $\mathrm{HexPly}^{\circledR}$ M91 and Ti6Al4V. However, the tensile properties of the SMPC lies in the range of the Aluminium alloys. The most important objective of a space habitat is to protect the space travellers from UV and particulate or ionizing radiation. Therefore, the mechanical properties of the SMPC is adequate to construct a habitat in order to fulfil that particular requirement.

However, in long-term such habitat can be damaged due to the presence of micrometeoroids travelling as fast as $60 \mathrm{kms}^{-1}$, space debris travelling at an average velocity of $10 \mathrm{kms}^{-1}$, vacuum $\left(1.33 \times 10^{-4}\right.$ to $\left.1.33 \times 10^{-7} \mathrm{~Pa}\right)$, ultraviolet (UV) radiation, particulate radiation, plasma, atomic Oxygen, temperature extremes and thermal cycling (from $-120{ }^{\circ} \mathrm{C}$ to $+120{ }^{\circ} \mathrm{C}$ ) [7]. Therefore, the impact energy absorbance, cycle life and creep behaviour of the carbon fibre reinforced SMPCs should be further investigated. Further improvements to the mechanical properties of SMPCs will enhance the lifetime of the space habitats and will provide more protection to the space travellers.

\subsection{Shape Memory Characteristics}

Figure 8 (a) illustrates the shape recovery sequence of a $90^{\circ}$ bended SMPC specimens due to $808 \mathrm{~nm}$ NIR radiation with $2 \mathrm{~W} / \mathrm{cm}^{2}$ intensity. This type of recovery occurs due the photothermal effect of the SMPC materials. The a
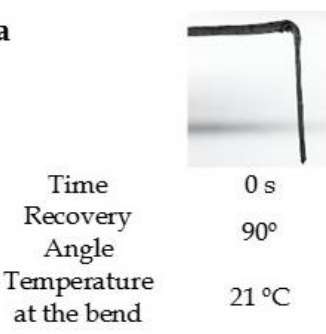

b

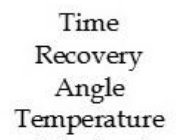

at the bend
$0 \mathrm{~s}$

$90^{\circ}$

$21^{\circ} \mathrm{C}$

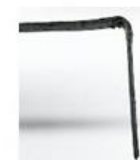

$10 \mathrm{~s}$

$92^{\circ}$

$58^{\circ} \mathrm{C}$

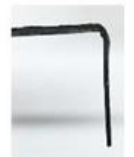

$0 \mathrm{~s}$

$90^{\circ}$

$21^{\circ} \mathrm{C}$

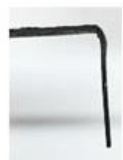

$3 \mathrm{~s}$

$92^{\circ}$

$66^{\circ} \mathrm{C}$

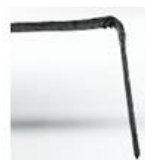

$20 \mathrm{~s}$

970

$78^{\circ} \mathrm{C}$

$6 \mathrm{~s}$

$110^{\circ}$

$82^{\circ} \mathrm{C}$

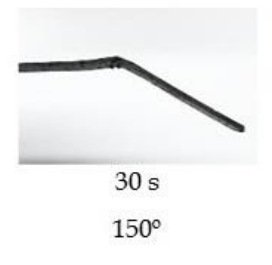

$129^{\circ} \mathrm{C}$
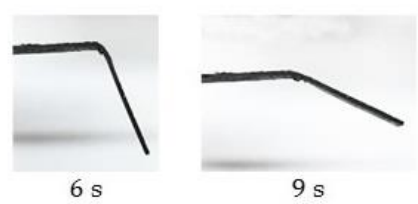

$153^{\circ}$

$93^{\circ} \mathrm{C}$

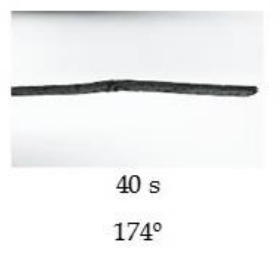

$134^{\circ} \mathrm{C}$

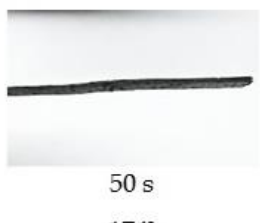

$176^{\circ}$

$137^{\circ} \mathrm{C}$
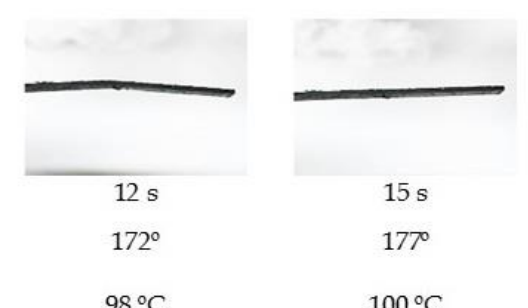

$177^{\circ}$

$100^{\circ} \mathrm{C}$

Figure 8 - Shape Recovery Behaviour the $90^{\circ}$ Bended SMPC and Respective Temperature at the Bend Location (a) Due to $808 \mathrm{~nm}$ NIR Radiation with $2 \mathrm{~W} / \mathrm{cm}^{-2}$ Intensity (b) Due to $150{ }^{\circ} \mathrm{C}$ Heated Air with $0.5 \mathrm{~m}^{3} / \mathrm{min}$ Flow Rate 
photothermal effect is a phenomenon which produces thermal energy from electromagnetic radiation. Once the electromagnetic radiation is absorbed by a material, free electrons of the material will vibrate at very high frequency, and reach higher energy levels. Part of the vibrational energy is transformed into kinetic energy of electrons and then converted into heat energy through the relaxation process between electrons and lattices. The rest is converted into electromagnetic waves and radiate outwards. Therefore, the carbon fibre reinforced SMPCs are capable absorbing $808 \mathrm{~nm}$ radiation and then convert it into heat. Figure 8 (b) illustrates the shape recovery sequence of a $90^{\circ}$ bended SMPC specimen due to $150{ }^{\circ} \mathrm{C}$ heated air with a 0.5 $\mathrm{m}^{3} /$ min flow rate. The total recovery time taken for NIR radiation is $50 \mathrm{~s}$ while the heated air has taken only $15 \mathrm{~s}$. Reason for the different recovery times is the dissimilarity of the supplied power. The NIR laser has provided $1.5 \mathrm{~W}$ power with a $2 \mathrm{~W} / \mathrm{cm}^{2}$ power density, whereas the heat gun has provided $\sim 2000 \mathrm{~W}$ power with $\sim 6002$ $\mathrm{W} / \mathrm{cm}^{2}$ power density. However, both types have facilitated the SMPC for almost full recovery. The specimen exposed to NIR radiation has recovered up to $176^{\circ}$ of $180^{\circ}$, while the specimen exposed to heated air has recovered up to $177^{\circ}$ of $180^{\circ}$. On average, both samples have demonstrated a $98 \%$ shape recovery. In addition, the angle recovery rates for NIR radiation and heated air are $3.52 \mathrm{deg} / \mathrm{s}$ and $11.8 \mathrm{deg} / \mathrm{s}$ respectively. Furthermore, the SMPC has demonstrated an excellent shape fixity, as the fixed angle for both tests were $90^{\circ}$, which is the angle the specimens were programmed into. The temperature at the bend location ( $3 \times 3$ pixel area) has been observed. As per the observations, due to NIR radiation, the temperature of the bend location has been increased from $21^{\circ} \mathrm{C}$ to $137^{\circ} \mathrm{C}$. Due to heated air the temperature of the bend location has been increased from $21^{\circ} \mathrm{C}$ to $100{ }^{\circ} \mathrm{C}$. The reason for higher temperature presented due to NIR radiation is the localized heating demonstrated by the NIR radiation at the bend location.

Figures 9 (a) and (b) illustrate the localised heating capability of the NIR radiation after being exposed to $10 \mathrm{~s}$ and $20 \mathrm{~s}$ respectively. The laser is focused to the bend location where the highest temperature was presented. However, as illustrated in Figure 9 (b) with time the heat has flowed to the free end of the specimen. Comparatively, the carbon fibres have higher thermal conductivity than the polymeric matrices, generally $24.0 \mathrm{~W} /(\mathrm{m} \cdot \mathrm{K})$ for graphite carbon fibres and $0.17-0.79 \mathrm{~W} /(\mathrm{m} \cdot \mathrm{K})$ for epoxy

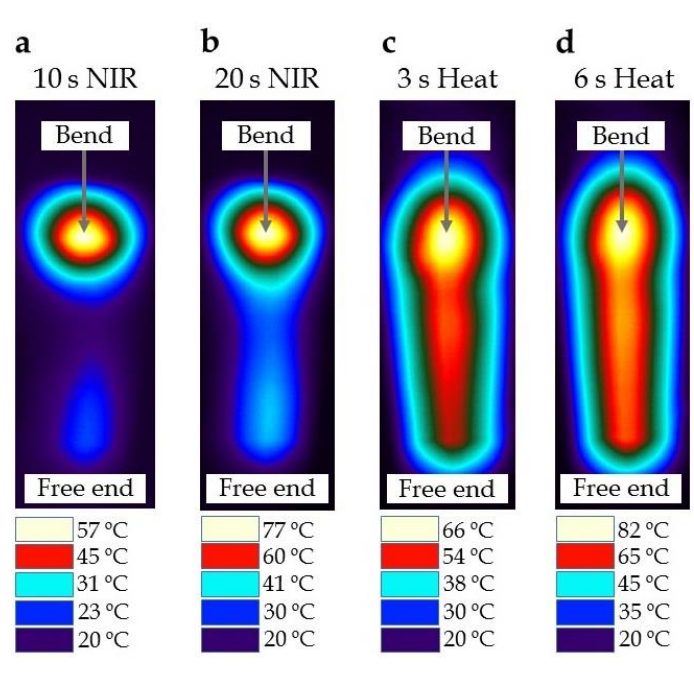

Figure 9 - Temperature Profile from Bend Location to Free End of the Specimen (a) After $10 \mathrm{~s}$ Exposer to NIR Radiation (b) After $20 \mathrm{~s}$ Exposer to NIR Radiation (c) After $3 \mathrm{~s}$ Exposer to Heated Air (d) After $6 \mathrm{~s}$ Exposer to Heated Air
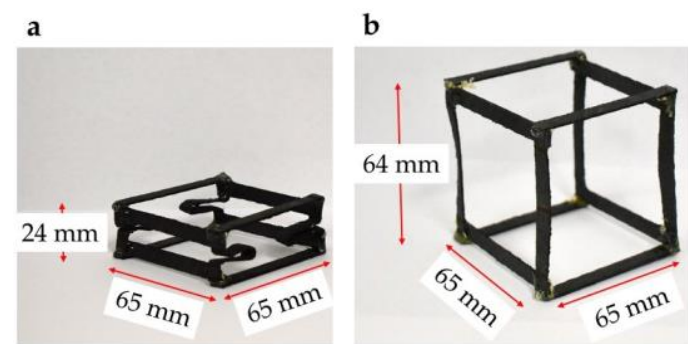

Figure 10 - Performance of the Model Deployable Structure (a) Programmed Shape (b) Recovered Shape after continuing for $18 \mathrm{~min}$ at $130{ }^{\circ} \mathrm{C}$ in $80 \mathrm{kPa}$ vacuum

matrices [17]. Therefore, the presence of carbon fibres caused to increase the temperature throughout the specimens even though the NIR radiation accomplished localized heating. Figures 9 (c) and (d) illustrate the temperature profiles from the bend location to free end of the SMPC specimen, after being exposed to heated air for $3 \mathrm{~s}$ and $6 \mathrm{~s}$ respectively. As per the illustrations, the heated air has increased the temperature of the entire surface. However, heating of the free end has no significance in this case. If the power of the laser is increased, the recovery rate due to NIR radiation will be increased. In that case, the laser will require less power than the heated air because of its ability for localized heating. Moreover, radiation is the most appropriate manner of activation for the SMPCs to be used in space applications, which are supposed to be operated in a vacuum. In comparison with heat, light enables the triggering of SMPs in a remote, localized and 


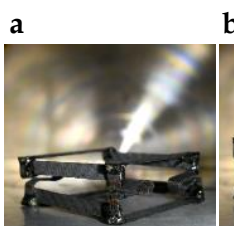

$0 \min$ b

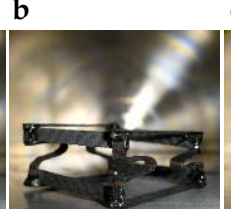

$3 \min$

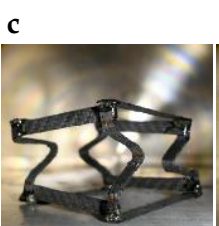

$6 \mathrm{~min}$ d

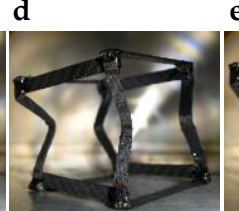

$9 \min$

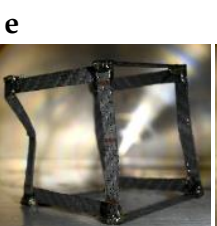

$12 \min$

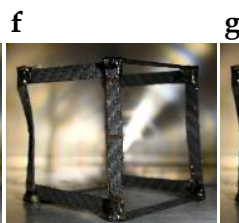

$15 \mathrm{~min}$

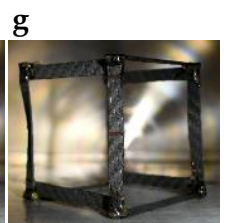

$18 \min$

Figure 11 - Shape Recovery Sequence of the Deployable Structure at $130^{\circ} \mathrm{C}$ in $80 \mathrm{kPa}$ Vacuum (a) Initial Programmed Shape (b - f) Shape Recovery Steps (g) Fully Recovered Shape

non-contact manner with neglected intervention on surrounding circumstance [18]. The most important advantages of using light to trigger molecular processes inside materials are that remote activation is possible since light can travel a long distance and spatially controlled activation is possible as the light beam (often a laser) can be delivered to selected areas. Also, light-triggered processes can be halted and resumed on demand by turning on-off or by controlling the power of the excitation light [19, 20].

\subsection{Performance of the Model Deployable Structure}

The deployable devices fabricated by using shape memory composites are able to undergo large deformations, which have been developed to make large structures fit into small volumes. Compared to other energy storing structures the SMPC made structures demonstrate less complexity, high strength and lightweight, which are advantageous for space engineering applications [20-22]. Moreover, such structures can demonstrate a controlled activation by noncontact manner $[18,20]$. The SMPCs have interesting features such as a strong temperature dependence of the material properties around $\mathrm{Tg}$ as well as a shape memory effect. Below $\mathrm{Tg}$, SMPCs are stiff, but upon being heated above $\mathrm{Tg}$ they are soft. Consequently, they can achieve large strains, be easily deformed and fixed to a desired configuration [21, 23].

The fabricated deployable structure has been programmed in to the shape shown in Figure 10 (a). Subsequently, as presented in Figure 10 (b), the shape of the deployable structure has been recovered, after continuing for $18 \mathrm{~min}$ at $130{ }^{\circ} \mathrm{C}$ in $80 \mathrm{kPa}$ vacuum. The recovery time is reasonably high compared to the $90^{\circ}$ bended experiments. The reason for such delay is the internal stress of the structural members. The $90^{\circ}$ bended experiments have been carried out under stress free strain recovery condition, since one end of the specimens stayed free. In the deployable structure both ends of the columns were jointed to beams. Furthermore, the weight of the top four beams has been supported by columns. The average length (L), width $(\mathrm{W})$ and height $(\mathrm{H})$ of the structure, before and after the recovery process have been measured and presented in Figure 10 (a) and (b) respectively. Although the expected programmed shape presented in Figure 4 (b) was $22 \mathrm{~mm}$ in height, the height of the actual programed shape shown in Figure 10 (a) was $24 \mathrm{~mm}$. The height of the recovered shape was $1 \mathrm{~mm}$ less than the original shape. The reason for that is the slight curvatures measured in the four columns of the recovered shape. Accordingly, the enclosed volume ( $\mathrm{L} \times \mathrm{W}$ $\mathrm{x} \mathrm{H}$ ) of the original shape, programmed shape and recovered shape were, $0.274625 \mathrm{~m}^{3}, 0.1014$ $\mathrm{m}^{3}$ and $0.2704 \mathrm{~m}^{3}$ respectively. The volume compression ratio during shape programming was $2.7: 1$ and volume expansion ratio during the shape recovery was $1: 2.66$. Figures 11 (a) to (g) illustrate the recovery sequence of the deployable structure in seven steps. It has been observed that columns have not been recovered uniformly. That is the reason for the buckled shape appeared from $6 \mathrm{~min}$ to $15 \mathrm{~min}$. The internal stress developed in each column has affected for its recovery rate. It is assumed that the each bend was equally exposed to heat as it was in an enclosed oven. However, in reality each bend location might not have heated equally. However, the recovery behaviour presented by the model structure is advantageous for deployable space habitats. As a result, the deployable space habitats can be fabricated on earth, compressed and packed in a spacecraft, transported to an outer space location and finally deployed in to the original shape. The importance of using SMPC materials for space habitat is that deployable structures can be fabricated as a single unit. There are no moving joints and assembly components. Space travellers do not need to engage with any assembling or construction work at space, which will save their time and energy. Furthermore, travellers do not need to take any tools or equipment for construction works. As per the presence of temperature or radiation in the space 
SMPC materials will be activated by its own once it is exposed to the surrounding. However, once deployed, the whole structure should be covered with a light reflective material (fabric / foil), which makes an enclosed living space for space travellers. Moreover, it will protect the structure from long-term radiation effects [24].

\section{Conclusions}

The carbon fibre reinforced shape memory polymer composite has shown $100 \%$ shape fixity and $98 \%$ shape recovery, which is crucial for deployable structures. However, the mechanical properties of the SMPC should be further improved in order to sustain in the harsh space environment. In addition to the typical activation by heating, the carbon fibre reinforced shape memory polymer composites can be activated by photothermal heating due to near infrared absorption. That behaviour is advantageous for remote and controlled activation in space environment. However, the absorption wavelengths of the carbon fibre reinforced SMPCs should be systematically investigated. Although the $90^{\circ}$ bended SMPC specimens demonstrated a fast recovery rate, a comparatively higher time has been taken by the deployable structure to accomplish the full recovery. That has happened due to the stress developed in the structural members. Therefore, the constrained strain stress recovery characteristics of the SMPC should be investigated in addition to the presented stressfree strain recovery characteristics. The deployable structure has been approximately compressed in to a three times smaller volume during the shape programming phase. Interestingly, it has been almost fully recovered to its original shape and volume after being at $130{ }^{\circ} \mathrm{C}$ and $80 \mathrm{kPa}$ vacuum for $18 \mathrm{mins}$. The volume compression and expandable behaviour presented by the SMPCs are crucial for deployable space habitats. It can be concluded that, the carbon fibre reinforced SMPCs can be used to produce deployable space habitats to fabricate on earth, compress and pack in a spacecraft, transport to an outer space location and ultimately deploy in to the original shape.

\section{Acknowledgement}

The authors are indebted to the Harbin Institute of Technology, China, for providing the materials used in this work.

\section{Funding}

This work was supported by the Asian Office of Aerospace Research and Development (AOARD), Air Force Office of Scientific Research (AFOSR), U.S. Air Force [grant number FA238616-1-4043].

\section{References}

1. Wessam, Al. A., Epaarachchi, J,A., Islam, M. \& Leng, J., "Implementation of a finite element analysis procedure for structural analysis of shape memory behaviour of fibre reinforced shape memory polymer composites", Smart Mater. Struct., Vol. 26, No. 12, October 2017, p. 125002.

2. Liu, Y., Lv, H., Lan, X., Leng, J. \& Du, S., “Review of electro-active shape-memory polymer composite", Compos. Sci. Technol., Vol. 69, No. 13, October 2009, pp. 2064-2068.

3. Leng, J., Lan, X., Liu, Y. \& Du, S., “Shape-memory polymers and their composites: Stimulus methods and applications", Prog. Mater Sci., Vol. 56, No. 07, September 2011, pp. 1077-1135.

4. Desroches, R. \& Smith, B., "Shape memory alloys in seismic resistant design and retrofit: a critical review of their potential and limitations", J. Earth. Eng., Vol. 08, No. 3, 2004, pp. 415-429.

5. Abrahamson, E. R., Lake, M. S. \& Gall, N. A. M. K., "Shape Memory Mechanics of an Elastic Memory Composite Resin", J. Intell. Mater. Syst. Struct., Vol. 14, No. 10, October, 2003, pp. 623-632.

6. Ohki, T., Ni, Q., Ohsako, N. \& Iwamoto, M., "Mechanical and shape memory behavior of composites with shape memory polymer", Composites Part A, Vol. 35, No. 09, September, 2004, pp. 1065-1073.

7. Finckenor, M.M. \& Groh, K. K. D., A Researcher's Guide to: Space Environmental Effects, NASA, 2017.

8. Liu, Y., Du, H., Liu, L. \& Leng, J., “Shape memory polymers and their composites in aerospace applications: a review", Smart Mater. Struct., Vol. 23, 2014, p. 023001.

9. Hinkle, J., Lin, J. \& Kling, D., “Design and Materials Study on Secondary Structures in Deployable Planetary and Space Habitats", 52nd AIAA/ASME/ASCE/AHS/ASC Structures, April, 2011.

10. ISO 527-5:2009, “Plastics - Determination of tensile properties - Part 5: Test conditions for unidirectional fibre-reinforced plastic composites", International Organization for Standardization, 2009-07. 
11. ASTM D6641 / D6641M-16e1, "Standard Test Method for Compressive Properties of Polymer Matrix Composite Materials Using a Combined Loading Compression (CLC) Test Fixture", ASTM International, West Conshohocken, PA, 2016.

12. Fejos, M. \& Karger-Kocsis, J., "Shape memory performance of asymmetrically reinforced epoxy/carbon fibre fabric composites in flexure", eXPRESS Polymer Letters, Vol. 07, 2013, pp. 528534

13. http://www.cytec.com/, Visited, 2018/06/10.

14. http://www.hexcel.com/, Visited, 2018/06/10

15. http://www.azom.com/, Visited, 2018/06/10

16. Kakei, A.A., Islam, M., Leng. J. \& Epaarachchi, J. A., "Use of an elasto-plastic model and strain measurements of embedded fibre Bragg grating sensors to detect Mode I delamination crack propagation in woven cloth $(0 / 90)$ composite materials", Structural Health Monitoring, Vol. 17, No. 02, March, 2017, pp. 363 - 378.

17. Joven, R., Das, R., Ahmed, A., Roozbehjavan, P. \& Minaie, B., "Thermal properties of carbon fiberepoxy composites with different fabric weaves", Proc., SAMPE, January, 2012.

18. Fang, L., Chen, S., Fang, T., Fang, J., Lu, C. \& Xu, Z., "Shape-memory polymer composites selectively triggered by near-infrared light of two certain wavelengths and their applications at macro-/microscale", Compos. Sci. Technol., Vol. 138, No. 18, January, 2017, pp. 106-116.

19. Habault, D., Zhang, H. \& Zhao, Y., "Lighttriggered self-healing and shape-memory polymers", Chem. Soc. Rev., Vol. 42, No. 17, 2013, pp. 7244-7256.

20. Herath, H.M.C.M., Epaarachchi, J.A., Islam, M.M., Al-Azzawi, W., Leng, J. \& Zhang, F., "Structural performance and photothermal recovery of carbon fibre reinforced shape memory polymer", Compos. Sci. Technol., Vol. 167, 2018, pp. 206-214.

21. Roh, J., Kim, H. \& Lee, S., “Viscoelastic effect on unfolding behaviors of shape memory composite booms", Compos. Struct., Vol. 133, 2015, pp. 235245 .

22. Herath, M., Epaarachchi, J., Islam, M. \& Leng, J., "Near Infrared Light Activated Shape Memory Polymer Composite for Space Applications", $11^{\text {th }}$ Asian-Australasian Conference on Composite Materials, July, 2018.

23. Herath, M., Al-Azzawi, W., Epaarachchi, J., Islam, M., Robertson, S., Leng, J. \& Zhang, F., “ThermoMechanical Behaviour and Shape Memory Characteristics of Carbon Fibre Reinforced
Epoxy", International Conference on Nanoscience and Nanotechnology, February, 2018.

24. Al Azzawi, W., Epaarachchi, J.A. \& Leng, J., "Investigation of ultraviolet radiation effects on thermomechanical properties and shape memory behaviour of styrene-based shape memory polymers and its composite", Compos. Sci. Technol., Vol. 165, 2018, pp. 266-273. 